\title{
Modelling the potential benefits of increased active travel
}

\author{
Paraic Carroll ${ }^{a}$, Brian Caulfield ${ }^{a}$, Aoife Ahern ${ }^{b}$ \\ ${ }^{a}$ Department of Civil, Structural and Environmental Engineering, Trinity College \\ Dublin, Ireland \\ ${ }^{\mathrm{b}}$ School of Civil Engineering, University College Dublin, Ireland
}

\begin{abstract}
This research examines the behavioural response of commuters within the Greater Dublin Area (GDA), Ireland, to a range of policy incentives designed to encourage travellers to make greater usage of sustainable travel modes for work. Several policy measures were evaluated using discrete choice and four stage modelling methods, to estimate the propensity of commuters to shift to active modes use (walking and cycling) rather than single occupancy vehicle (SOV). As a means of appraising the hypothetical introduction of a range of active mode policy incentives, a stated preference experiment (SP) was created as an instrument for gathering decision making, mode choice and socio-demographic data from a sample of commuters in the GDA, based on a number of designed policy scenarios. Extensive transport modelling work was subsequently conducted with the National Transport Authority (NTA) of Ireland using the National Regional Modelling System (RMS). A representation of the policy changes explored in the SP experiment were made in this four-stage transport model in order to produce real life estimates of trip making behaviour and mode share, to test the behavioural response of the introduction of the policy incentives. Changes to parameters in the Mode Choice and Trip Assignment stages of the four-stage model were made to account for improvements made to infrastructure and time attributes of walking and cycling in the model. The modifications were made based on 'Do Nothing/ Base', 'Do Something', and 'Do Maximum' scenarios, which were determined by attribute level values taken from the SP survey.
\end{abstract}

The findings produced in this study show a marked inelasticity of commuters to react in response to improvements made to the level of service of cycling, while on the contrary exhibiting high levels of elasticity to changes made to pedestrian infrastructure. Outputs from these model scenarios found that pedestrians in the GDA were most sensitive to the policy incentives tested. The results highlight that investing in improvements to the public realm may be a more worthwhile investment in order to encourage a modal shift to walking for commuting trip purposes.

Please cite as: Carroll, P., Caulfield, B., Ahern, A., Modelling the potential benefits increased active travel, Transport Policy, 79, 2019, p82 - 92

\section{Introduction}

Car dependency and the dominance of single occupancy vehicle (SOV) use as a transport mode for commuting and other purposes presents a number of costly economic and environmental consequences for urban areas, such as the associated effects of traffic congestion, air and noise pollution (Washbrook et al. 2006). The World Health Organisation (WHO) estimates that the total economic cost of respiratory health and mortality associated with air pollution amounts to $€ 1.45$ trillion per annum, of which transport accounts for 19.5\% (11.3 Megatons of $\mathrm{CO}_{2}$ ) in Ireland in 2014 (Environmental Protection Agency (EPA), 2016; WHO, 2015). Of the emissions produced from transport in Ireland, it is estimated that the private car accounts for 52\% (Department of Public Expenditure and Reform (DPER), 2018). In 
this way, there is an urgency to act and find ways of stimulating modal shifts to alternative sustainable modes in order to alleviate these adverse effects (DPER, 2018; NTA, 2016). International agreements set by the United Nations Kyoto Protocol (1998), the Intergovernmental Panel on Climate Change (IPCC) (2007) and the European Commission (2012), to reduce emissions by $50 \%$ from 1990 levels by 2020 and at least $80 \%$ by 2050 (European Commission, 2012), act as important incentives to take action in order to avoid legally binding financial penalties. However, it has been accepted that Ireland will most certainly fail to meet its 2020 target, as $\mathrm{CO}_{2}$ emissions alone are projected to increase by $10 \%$ by this time, which is a clear indication that not enough is currently being done to decarbonise the Irish economy.

To provide a comparison, two of the countries with the highest walking and cycling rates in Europe (Denmark and The Netherlands) are compared to Ireland in Table 1. Table 1 contains the mode share in the two largest cities in each country and the 2014 values for tonnes of $\mathrm{CO}_{2}$ per capita for each of the three countries. The results clearly show that Ireland lags behind both Denmark and the Netherlands in terms of both modal share of walking and cycling and that Ireland's emissions per capita is greater than both other countries. This comparison does not claim to be exhaustive, rather it serves to illustrate how countries with the highest sustainable mode share in cities can also have much lower emission per capita.

Table 1 Emissions and sustainable mode share comparison

\begin{tabular}{|c|c|c|c|c|c|}
\hline \multirow[t]{2}{*}{ Country } & \multirow[t]{2}{*}{ City } & \multirow{2}{*}{$\begin{array}{l}\left(\mathrm{tCO}_{2} / \mathrm{cap}\right) \\
2014^{*}\end{array}$} & \multicolumn{2}{|c|}{ Modal Share** } & \multirow{2}{*}{$\begin{array}{l}\text { Total sustainable } \\
\text { mode share }\end{array}$} \\
\hline & & & Walk & Cycle & \\
\hline \multirow{2}{*}{$\begin{array}{l}\text { The } \\
\text { Netherlands }\end{array}$} & Amsterdam & \multirow[t]{2}{*}{1.75} & $20 \%$ & $22 \%$ & $42 \%$ \\
\hline & Rotterdam & & $18 \%$ & $16 \%$ & $34 \%$ \\
\hline \multirow[t]{2}{*}{ Denmark } & Copenhagen & \multirow[t]{2}{*}{1.93} & $17 \%$ & $30 \%$ & $47 \%$ \\
\hline & Aarhus & & $19 \%$ & $18 \%$ & $37 \%$ \\
\hline \multirow[t]{2}{*}{ Ireland } & Dublin & \multirow[t]{2}{*}{2.27} & $15 \%$ & $7 \%$ & $22 \%$ \\
\hline & Cork & & $15 \%$ & $2 \%$ & $17 \%$ \\
\hline
\end{tabular}

Sustainable travel measures seek to modify travel behaviour change in favour of green alternatives such as active modes (walking and cycling), public transport and smarter use of the private car, namely, car-sharing and carpooling. In this research a stated preference (SP) survey was constructed to gather mode choice preferences and to test the propensity of respondents to switch from car trips to active modes.

The results of this SP experiment were then used to infer parameter modifications made to the National Transport Authority's ${ }^{1}$ (NTA) Eastern Regional Model(ERM) ${ }^{2}$. Changes to parameters in the mode choice and trip assignment stages of the ERM were made to account for improvements made to infrastructure, frequency, time and cost attributes of various modes included in the model. The changes were made based on 'Do Something', and 'Do Maximum' scenarios, determined by attribute level values from the SP survey, for the 2012 Base Scenario.

The evaluation approach in this paper merges behavioural outputs with a traditional four-stage model. This step enables policymakers to gain a greater understanding of some of the real-world implications of promoting behaviour change.

\footnotetext{
${ }^{1}$ The National Transport Authority is a statutory non-commercial body, which operates under the aegis of the Department of Transport, Tourism and Sport (DTTAS) of Ireland.

${ }^{2}$ Travel demand model that predicts all day (AM to OP periods) for a range of modes in the region of Leinster, which includes the GDA.
} 


\section{Study Area and challenges}

Sustainable travel within the GDA has experienced a resurgence in recent years (Transport for Ireland, 2017; NTA, 2016; Caulfield, 2014), in line with increasing numbers of people commuting to work, which rose from 1.13 million in 2011 to 1.17 million in 2016 (CSO, 2017). The 2016 Census results similarly revealed an increase in PT usage of $15 \%$, with an additional 9,264 commuters opting to travel by bus and rail modes to work and education in the GDA (CSO, 2017; Carroll et al. 2017a). Furthermore, between 2006 and 2016 the mode share of cycling grew most across all modes, with an increase of $60 \%$ in Dublin city, as 12,089 cyclists crossed the canal cordons of the city, representing an increase of 7,250 in 2016. These counts are taken on an annual basis and this upward trend has been evident for the past 10 years.

Many reasons have been attributed to this increase in cycling (Caulfield, 2014). Since 2006, Dublin has significantly invested in cyclist infrastructure with over $500 \mathrm{~km}$ of cycle lane (NTA, 2013) under a new infrastructure plan for the city plans to introduce over $200 \mathrm{~km}$ of new cyclist infrastructure (NTA, 2019). Dublin City Council has also rolled out $30 \mathrm{kmph}$ speed zones in extensive parts of the city to encourage cycling and walking (Dublin City Council, 2017). Other additions to the policy mix in the city over the past decade have been a very successful Bike Sharing scheme (Pillar et al. 2016) and a tax-free loan scheme to purchase bicycles and cycling equipment (Caulfield and Leahy, 2011). However, the same level of investment has not been realised in improving pedestrian facilities and the city still lacks walking strategies.

At the same time, a $13 \%$ decrease in private cars $(6,756$ fewer cars commuting) was also found. However, during this period, an overall increase in private car usage in the other GDA counties was observed, as those commuting by car to work in the GDA increased from 406,725 in 2006 to 441,147 in 2016, which represented $37 \%$ of the mode share (CSO, 2017). As a result of this, traffic congestion has grown significantly, with average traffic speeds falling by $5.5 \%$ between 2014 and 2015 in Dublin and by $18 \%$ in the GDA in 2016 in the AM peak (NTA, 2018). In 2018, Dublin was found to be the third worst city in the world for hours lost in congestion (INREX, 2019). Ireland has also been shown recently to be the second worst in the EU for tackling climate change (Climate Action Network Europe, 2019). This increase in congestion and a poor record for addressing climate change are some of the main motivations for this research. The work attempts to examine how further uptake of walking and cycling could contribute to reducing congestion and lowering emissions.

\section{Literature Review}

The literature in the area of promoting active modes of transport has expanded rapidly over the past decade. Yet, the issues which impact on of pedestrian route choice and determine level of service are challenging to quantify, such as streetscape, signage and retail frontage and architecture (Guo and Loo, 2013). These elements are central to encouraging an increase in pedestrian activity as Guo and Loo (2013) examine the feasibility of modelling pedestrian route choice behaviour in New York City and Hong Kong using revealed route choice models. The modelling of route choices in New York showed that sidewalk width and open space increased the likelihood of such routes being chosen, which could be used as a means of increasing the mode share of walking. Traffic volume was negatively correlated with route choice. In other words, routes with high levels of traffic, predictably, reduced the probability of pedestrians choosing such routes. In the Hong Kong model, the number of street crossings and the presence of retail frontage/ 
facade was found to be valued by pedestrians and increased the likelihood of routes with a high proportion of these features being chosen by individuals. This study outlines the importance that features present in the public realm in pedestrian route choice as they impact on perceptions of safety, comfort and walkability.

Hine (1996) similarly highlights the effect that adjacent traffic speed and flow can have on pedestrian activity as a number of in-depth interviews were conducted to explore pedestrian perceptions of and behavioural response to traffic flow conditions in Edinburgh, Scotland. The flow of traffic is referred to as a traffic barrier in this study, which can, at high levels and low speeds, present a physical obstacle to pedestrians and cause pedestrian congestion on footpaths, delays and dangerous crossing behaviour at unsuitable crossing points. In a similar study, Guo (2009) conducted a study of egress path choices of subway commuters in Boston from subway stations to workplaces. In this study, the pedestrian environment was considered as the determinant factor in the utility of walking. Path choice is the examination of individual route decision making in a choice set of multiple options with matching origin and destination pairs. The trade-off behaviour of commuters in downtown Boston was assessed based on design variables of the pedestrian environment. The attributes considered were: the density or flow along paths, footpath width, pedestrian flow at junctions, the availability of open space and the topography of the route. Using these characteristics, the causal relationship between the pedestrian environment and the utility of walking was investigated in a binary logit model. The findings of this model showed that higher footpath densities and wider footpaths would result in an increase in the likelihood of pedestrians opting for the route. This preparedness to walk given the availability of the footpath characteristics led to people opting to walk longer distances, which may enlarge the catchment of a public transport system (Guo, 2009). This research confirmed that the pedestrian environment does affect the utility of walking, to the extent that a $21-33 \%$ increase in walking could be achieved in the study area examined, which was outlined as sufficient to warrant policy intervention. Indeed, evidence such as this has shown that the quality and or level of service of the public transport mode can similarly result in individuals walking further to get to the service (O'Connor and Caulfield, 2018).

Muraleetharan et al. (2005), examined the pedestrian environment to determine varying pedestrian behaviour and level-of-service at crossings and junctions in Sapporo, Japan. In this study, factors such as available space at crossing facilities, the turning axis of motorised vehicles, signalling times and pedestrian-bicycle interactions are analysed for their effect on pedestrian level-of-service (LOS) at junctions in a multi-variable regression model. The results of the regression model found that the turning vehicle factor effected the pedestrian LOS most. This meant that as the number of turning vehicles increased, the perceived level of pedestrian safety decreased. In addition to this, the results showed that signalling delays and the interaction of pedestrian and motorised vehicles, and pedestrians and bicycles were statistically significant factors at junctions. A number of suggestions for improving the junctions were proposed by the respondents surveyed, in which they favoured high visibility crossing enhancements and segregated paths for bicycles in order to increase the perceived level of safety at the crossings. This pedestrian LOS model expresses the safety concerns of pedestrians in large urban areas and offers an effective approach of determining the performance of crossing facilities from the perspective of pedestrians, which is a valuable input in the planning process.

The increase in the popularity of cycling in many European and American cities, particularly in the past decade, has been represented by a surge in cycling research being produced in academia, with an average increase in academic publications from 197 annually in the period of 1991- 1995 to 610 per year in 2011-2016 (European 
Cyclists' Federation, 2017; Pucher and Buehler, 2017). There has also been significant research in recent years to explore methods to improve cycling conditions and increase usage. Abraham et al. (2002) assessed the attractiveness of a cycling in Calgary, using a SP survey, in response to proposed improvements being made to travel times on different categories of cycling facilities (i.e. shared and segregated cycle lanes), in addition to the availability of cycle-friendly facilities at the destination (e.g. secure parking and showers/ locker rooms). The results from this study found that while cyclists prefer routes that offer short trip times, cyclists would also be prepared to travel longer distances on routes providing proper cycling infrastructure and destination amenities. In other words, cyclists would be willing to make a tradeoff between shorter trip times and the incidence of improved cycling infrastructure. Conversely, results produced by Pooley et al. (2013) determined that safety concerns, familial responsibilities and social perceptibility of cycling by family and peers were prime reasons negatively affecting the likelihood of choosing cycling as a mode.

Stinson and Bhat (2003) similarly explored the topic of cycle route choice with the use of a SP survey, as a method of examining the potential of increasing the mode share of active modes to reduce car usage in Austin, Texas. In this study, it is outlined that two types of factors determine cycling mode choice decisions, namely: link and route-level factors. Link-level factors consist of the availability of cycling infrastructure, the presence or volume of road traffic adjacent to cycle routes and the physical condition of the infrastructure. Route-level factors consider the continuity of cycle lanes and the average trip time on such routes, based on the presence of traffic management measures and the number of junctions etc. Improvements to link and route- factors were then used as the policy measures that impact on the trip characteristics in the SP survey. The link-level results from this study found that cyclists preferred residential routes with low traffic volumes, partly separated from motorised traffic and as expected, smooth riding surfaces were preferred over rough and coarse surfaces. The route-level findings demonstrated that there was a high preference for continuous cycle routes with few traffic controls (i.e. traffic lights, stop signs) and routes without large intersections or junctions. Finally, Stinson and Bhat (2003) determined that travel time was the trip attribute of most interest to cycling commuters with segregated cycling infrastructure following, which was in line with the results produced in the experiment presented in this paper below.

In a similar study, Caulfield et al. (2012) conducted a SP study that examined the infrastructure preferences of cyclists in the Dublin, Ireland. A number of infrastructure and route attributes or characteristics such as the type of infrastructure, the number of junctions on the route, the volume of cyclist traffic and adjacent traffic speed were tested in this survey to determine the impact of such factors on the utility of cycling. The trade-off behaviour between attributes and attribute levels included in the study were utilised to elicit infrastructure and route preferences, that were modelled in a Multinomial logit (MNL) model. The results of this analysis found that short travel times (i.e. 10 mins), with a statistically significant coefficient at the $95 \%$ confidence interval, was the preferred attribute tested, based on the positive sign and the size of the coefficient. This meant that lower trip times would result in higher increases in the utility of cycling in the model. Furthermore, routes with a $30 \mathrm{~km} / \mathrm{h}$ speed limit imposed, in addition to the availability of off road and greenway cycle facilities, were also found to increase the likelihood of individuals choosing cycling as a mode in Dublin.

Li et al. (2017) examine cyclist route choice behaviour using data generated from a smartphone application in Toronto, Canada, which was evaluated in a MNL model of commuting trips preferences. Observed cycling decisions were collected from a purposely designed smartphone application developed to monitor cycling data 
through a built-in GPS used in conjunction with cartographic data provided by Toronto's Open Data portal ( $\mathrm{Li}$ et al. 2017). Based on data collected in the smartphone app, route choice sets were created by comparing a number of alternative cycling routes with the observed routes from the GPS data. Key cycle route characteristics were then applied to the chosen route to form the utility function of the MNL model. Some of the main factors considered were: route distance, energy consumption, number of PT stops, traffic volumes and the levels of cycling infrastructure/ facilities on the route. This model was then replicated for alternative routes with matching origins and destinations in order to compare the revealed sample model with other possible routes that could be chosen by respondents. This comparison was ultimately used to determine preferences for cycling infrastructure and route choices as a means of generating recommendations for infrastructure planning. The results of this analysis found that shorter distance routes with less traffic volumes and segregated or off-road cycling infrastructure were preferred, consequently increasing the likelihood of routes with these features being chosen.

In short, research so far in both walking and cycling emphasises the importance of infrastructure and immediate environment or surroundings in encouraging individuals to use both modes. However, a key underling factor affecting the potential uptake of walking and cycling is the convenience of private car use, and Pooley et al. (2011) state that increasing the mode share of active modes is unlikely without placing restrictions on car use and addressing the 'complexities of everyday life'. The research described in this paper further explores this area to enrich our understanding of the incentives that might bring about increased walking and cycling. The main contribution to knowledge of the work is that both a SP survey and network modelling are used, the results produced from the MNL modelling of the SP respondents are utilised to inform parameter changes to a four-stage transport model (FSM) in order to produce behavioural inferences at socio-demographic and mode share level. Policy appraisal is thus examined by utilising behavioural elicitations from SP (i.e. regression coefficients, cross tabulation and chi-square statistics, etc.) to guide parameter modifications to a FSM in order to produce real life estimates of mode share and trip making behaviour. Previous research has tended to use SP studies to look at this, without using network modelling. The approach used in this paper provides a direct comparison between walking and cycling incentives. Using FSM planning tool, this study presents the probability of mode share changes arising from investment in active modes.

This work could be conceivably be replicated elsewhere subject to the availability of a national dataset such as a Census of population and household travel data primarily, which were the used in the network modelling, and collection of both SP and revealed preference survey data.

\section{Methods}

\subsection{Study Area}

The study area examined in this paper is the GDA, containing the counties of Dublin, Meath, Kildare and Wicklow. The total population of the GDA was 1,907,332 (CSO, 2017), which represented $40.05 \%$ of the total population of Ireland at the time of the last census in $2016(4,761,865)$. The GDA was designated as the most suitable area for this research in Ireland, as a result of there being a greater assortment of alternate and sustainable transport modes available in this region relative to the rest of Ireland. For instance, there are more options available and infrastructure in place to realistically offer viable alternatives to the private car, such as active mode infrastructure, a number of rail-based public transport (PT) modes (such as the 
$\mathrm{DART}^{3}$ and the Luas ${ }^{4}$ ), a number of bus operators, and the availability of bikesharing, car-sharing and carpooling services. While the GDA was determined as the optimal study area in Ireland for this research, it was also considered that this study could conceivably be replicated elsewhere in Ireland or indeed outside of Ireland. This it is however subject to the sufficient availability of alternative transport modes to the private car, ideally in urban areas. For further information on the methods and models used in this paper please refer to Carroll et al. (2017b).

\subsection{Survey Design}

For active modes, Short and Caulfield (2014) and Pooley et al. (2013) examined the challenge of ensuring safety along cycling routes and identified speed and available infrastructure as necessary attributes and the main perceived risk factors associated with cycling. This was specifically in relation to increasing the segregation between cyclists and other traffic, consequently leading to short trip times and the enhancement of the image of cycling as a safe and sustainable form of transport. Caulfield et al. (2012) supported this, as it was concluded that segregated infrastructure was the preferred form of cycling infrastructure from the results of an SP experiment, which was followed by cycle routes through residential streets and parks, where lower speed limits and traffic levels were the norm. In this paper, the infrastructure attribute was presented on three levels: $20 \%, 40 \%$ and $60 \%$ to account for low, medium and high levels of infrastructure coverage in the GDA. The levels of infrastructure were defined in reference to SP studies such as: Guo and Loo, (2013); Tilahun et al. (2007); Brown et al. 2007; Abraham et al. (2002), Stinson and Bhat (2003); Bovy and Bradley (1985), and Hopkinson and Wardman (1996), whom determined that surface quality, facility type, and adjacent traffic levels, assessed on various attributes levels, were the main considerations of potential active modes commuters. The purpose of these levels was to consider how individuals value pedestrian and cycling infrastructure, i.e. the facilities available on certain routes in the network.

Lowering urban traffic speeds was also found to be associated with reducing serious injury rates and this was correlated with accident severity, which generally increases with speed (Short and Caulfield, 2014; Nilsson, 2004). It was similarly determined in this literature that only $5 \%$ of collisions are severe in $30 \mathrm{~km} / \mathrm{h}$ zones, thus, justifying 'adjacent traffic speed' is a main policy variable to be considered with cycling and walking. It was decided to present the adjacent traffic speed attribute at the levels of: $50 \%, 75 \%$ and $100 \%$ of a trip with a $30 \mathrm{~km} / \mathrm{h}$ speed limit, for two reasons: 1 ) given the 0-5 kms distance that most commuters were found to walk and cycle within for commuting purposes from home to work or education (Caulfield, 2014; NTA, 2013); and 2) considering that there is already a $30 \mathrm{~km} / \mathrm{h}$ speed limit in many residential and urban areas in the inner and outer metropolitan area of the GDA (Dublin City Council, 2017). As a result of this review, infrastructure, time and adjacent traffic speed were selected as the mode-specific attributes to be modelled in the Active Modes Model, which is shown in Table 2 .

\footnotetext{
${ }^{3}$ Dublin Area Rapid Transit heavy rail service

${ }^{4}$ Dublin's light rail/ tram service
} 
Table 2 Active Modes Model - alternatives, attributes and attribute levels

\begin{tabular}{|c|c|c|c|}
\hline \multicolumn{4}{|c|}{ Active Modes Model } \\
\hline Mode & Attribute & Policy Incentives & Attribute Level \\
\hline \multirow{9}{*}{ Walk } & \multirow{3}{*}{ Infrastructure } & \multirow{3}{*}{$\begin{array}{l}\text { Widening of and evenly } \\
\text { surfacing footpaths, reduction } \\
\text { of street clutter and improved } \\
\text { street lighting. }\end{array}$} & $\begin{array}{l}20 \% \text { of trip with even surfaced, } \\
\text { widened paths, separated from traffic }\end{array}$ \\
\hline & & & $\begin{array}{l}40 \% \text { of trip with even surfaced, } \\
\text { widened paths, separated from traffic }\end{array}$ \\
\hline & & & $\begin{array}{l}60 \% \text { of trip with even surfaced, } \\
\text { widened paths, separated from traffic }\end{array}$ \\
\hline & \multirow{3}{*}{ Time } & \multirow{3}{*}{$\begin{array}{l}\text { Reduce pedestrian waiting } \\
\text { times at junctions by } \\
\text { increasing signalling times } \\
\text { given. }\end{array}$} & 2 minutes off trip time \\
\hline & & & 4 minutes off trip time \\
\hline & & & 6 minutes off trip time \\
\hline & \multirow{3}{*}{$\begin{array}{l}\text { Adjacent } \\
\text { Traffic Speed }\end{array}$} & \multirow{3}{*}{$\begin{array}{l}\text { Reduction in speed limit to } \\
30 \mathrm{~km} / \mathrm{h}\end{array}$} & $50 \%$ of trip with $30 \mathrm{~km} / \mathrm{h}$ speed limit \\
\hline & & & $75 \%$ of trip with $30 \mathrm{~km} / \mathrm{h}$ speed limit \\
\hline & & & $100 \%$ of trip with $30 \mathrm{~km} / \mathrm{h}$ speed limit \\
\hline \multirow{9}{*}{ Cycle } & \multirow{3}{*}{ Infrastructure } & \multirow{3}{*}{$\begin{array}{l}\text { Increase cycle lane continuity } \\
\text { and incidence of fully } \\
\text { segregated cycle lanes }\end{array}$} & $20 \%$ of trip fully segregated from traffic \\
\hline & & & $40 \%$ of trip fully segregated from traffic \\
\hline & & & $60 \%$ of trip fully segregated from traffic \\
\hline & \multirow{3}{*}{ Time } & \multirow{3}{*}{$\begin{array}{l}\text { Cyclist priority and early starts } \\
\text { at major junctions }\end{array}$} & 2 minutes off trip time \\
\hline & & & 4 minutes off trip time \\
\hline & & & 6 minutes off trip time \\
\hline & \multirow{3}{*}{$\begin{array}{l}\text { Adjacent } \\
\text { Traffic Speed }\end{array}$} & \multirow{3}{*}{$\begin{array}{l}\text { Reduction of speed limit to } \\
30 \mathrm{~km} / \mathrm{h}\end{array}$} & $50 \%$ of trip with $30 \mathrm{~km} / \mathrm{h}$ speed limit \\
\hline & & & $75 \%$ of trip with $30 \mathrm{~km} / \mathrm{h}$ speed limit \\
\hline & & & $100 \%$ of trip with $30 \mathrm{~km} / \mathrm{h}$ speed limit \\
\hline
\end{tabular}

\subsection{Data collection and sample collected}

The SP survey was conducted online in March 2017. It was distributed randomly by a survey company to a sample of the population who both live and work/study in the GDA. Potential respondents were approached by email, which included an introduction to the research and experiment to be conducted, additionally a brief description of what the results would be used for and a statement of data anonymisation was also provided. In order to ensure that the sample approached were from across the GDA an initial short survey questionnaire was created, which established the respondent's county of residence. Respondents who were living outside of the defined GDA were screened out, and those who stated residence within the GDA were automatically redirected to the main survey. The survey was sent to a total 5,028 people, of which 1,051 completed the initial county screener questionnaire, resulting in a response rate of $20.9 \%$. In total there were 683 respondents from the GDA, 432 of whom fully completed the survey. In order to 
achieve a close to equal gender representation (see Table 3), reminder notices were issued, with a focus on male non-respondents.

A summary of the socio-demographic characteristics of the sample are presented in Table 3. The survey data collected are compared with Census 2016 data in order to link the survey results with state figures for the same region to ensure that the sample was representative of the population of the GDA. From this data, it can be observed that a greater percentage of the sample were aged within the 35-44 and 45-54 years old cohorts (compared to the 2016 Census), with at least a secondary school education, married with no children, an average household income of between $€ 24,999$ to 49,999 per annum, living in the inner suburbs of Dublin and working in Dublin city centre. The gender split, in addition to the age ranges, number of children/ dependents, level of educational attainment, marital and economic status characteristics of the sample were found to be adequate representations of the population of the GDA when compared with the 2016 Census results for the GDA, thus verifying the authenticity of the sample recorded (CSO, 2017).

Table 3 Characteristics of the sample

\begin{tabular}{|c|c|c|c|c|c|c|c|c|c|}
\hline Variable & \multicolumn{2}{|c|}{ Survey } & \multicolumn{2}{|c|}{ Census 2016 (GDA) } & Variable & \multicolumn{2}{|c|}{ Survey } & \multicolumn{2}{|c|}{ Census 2016 (GDA) } \\
\hline Gender & $\mathrm{N}$ & $\%$ & $\mathrm{~N}$ & $\%$ & Marital Status & $\mathrm{N}$ & $\%$ & $\mathrm{~N}$ & $\%$ \\
\hline Male & 193 & 44.68 & 935,849 & 49.07 & Single & 179 & 41.53 & $1,055,977$ & 55.36 \\
\hline Female & 239 & 55.32 & 971,483 & 50.93 & Married & 215 & 49.88 & 693,749 & 36.37 \\
\hline Total & 432 & 100.00 & $1,907,332$ & 100.00 & Separated & 19 & 4.41 & 46,127 & 2.42 \\
\hline & & & & & Divorced & 15 & 3.48 & 41,373 & 2.17 \\
\hline Age & & & & & Widowed & 3 & 0.70 & 70,106 & 3.68 \\
\hline $18-24$ years old & 38 & 8.80 & 168,686 & 11.68 & Total & 431 & 100.00 & $1,907,332$ & 100.00 \\
\hline $25-34$ years old & 84 & 19.44 & 304,968 & 21.12 & & & & & \\
\hline $35-44$ years old & 114 & 26.39 & 315,197 & 21.83 & Children/ dependents & & & & \\
\hline $45-54$ years old & 109 & 25.23 & 242,078 & 16.76 & None & 199 & 46.96 & 140,349 & 29.17 \\
\hline $55-64$ years old & 67 & 15.51 & 186,756 & 12.93 & One & 65 & 15.01 & 136,252 & 28.32 \\
\hline $65+$ years old & 20 & 4.63 & 226,362 & 15.68 & Two & 98 & 22.63 & 124,728 & 25.93 \\
\hline Total & 432 & 100.00 & $1,444,047$ & 100.00 & Three & 49 & 11.32 & 57,916 & 12.04 \\
\hline & & & & & More than 3 & 22 & 5.08 & 21,817 & 4.54 \\
\hline Education & & & & & Total & 433 & 100.00 & 481,062 & 100.00 \\
\hline $\begin{array}{l}\text { No formal education/ } \\
\text { training }\end{array}$ & 3 & 0.69 & 16,711 & 1.46 & & & & & \\
\hline Primary education & 8 & 1.84 & 113,325 & 9.93 & Economic Status & & & & \\
\hline Secondary education & 130 & 29.89 & 369,637 & 32.40 & $\begin{array}{l}\text { Working for payment or } \\
\text { profit }\end{array}$ & 267 & 61.81 & 853,116 & 55.25 \\
\hline Technical or vocational & 46 & 10.57 & 99,092 & 8.68 & $\begin{array}{l}\text { Looking for first regular } \\
\text { job }\end{array}$ & 8 & 1.85 & 54,951 & 3.56 \\
\hline $\begin{array}{l}\text { Advanced Certificate/ } \\
\text { Completed Apprenticeship }\end{array}$ & 26 & 5.98 & 63,322 & 5.55 & Unemployed & 24 & 5.56 & 99,248 & 6.43 \\
\hline Higher Certificate & 49 & 11.26 & 59,886 & 5.25 & Student & 24 & 5.56 & 164,621 & 10.66 \\
\hline $\begin{array}{l}\text { Ordinary Bachelor } \\
\text { Degree/ Diploma }\end{array}$ & 66 & 15.17 & 99,679 & 8.73 & $\begin{array}{l}\text { Looking after home/ } \\
\text { family }\end{array}$ & 40 & 9.26 & 115,164 & 7.46 \\
\hline Honours Bachelor Degree & 55 & 12.64 & 156,350 & 13.70 & Retired & 36 & 8.33 & 197,761 & 12.81 \\
\hline $\begin{array}{l}\text { Postgraduate Diploma/ } \\
\text { Degree }\end{array}$ & 48 & 11.03 & 147,700 & 12.94 & $\begin{array}{l}\text { Unable to work due to } \\
\text { permanent sickness or } \\
\text { disability }\end{array}$ & 17 & 3.94 & 53,890 & 3.49 \\
\hline Doctorate (PhD) or Higher & 4 & 0.92 & 15,550 & 1.36 & Other & 16 & 3.70 & 5,350 & 0.34 \\
\hline Total & 435 & 100.00 & $1,141,252$ & 100.00 & Total & 432 & 100.00 & $1,544,101$ & 100.00 \\
\hline Income ${ }^{*}$ & & & & & Living Location & & & & \\
\hline$€ 24,999$ or less & 110 & 25.29 & & & Dublin City Centre & 55 & 12.70 & & \\
\hline$€ 25,000-49,999$ & 129 & 29.66 & & & Inner Suburbs & 141 & 32.56 & & \\
\hline$€ 50,000-74,999$ & 74 & 17.01 & & & Outer Suburbs & 101 & 23.33 & & \\
\hline$€ 75,000-99,999$ & 27 & 6.21 & & & Commuter Town & 78 & 18.01 & & \\
\hline$€ 100,000$ or more & 17 & 3.91 & & & Rural Area & 58 & 13.39 & & \\
\hline I'd rather not say & 78 & 17.93 & & & Total & 433 & 100.00 & & \\
\hline Total & 435 & 100.00 & & & & & & & \\
\hline & & & & & Working location* & & & & \\
\hline & & & & & Dublin City Centre & 135 & 33.75 & & \\
\hline & & & & & Inner Suburbs & 116 & 29.00 & & \\
\hline & & & & & Outer Suburbs & 67 & 16.75 & & \\
\hline
\end{tabular}




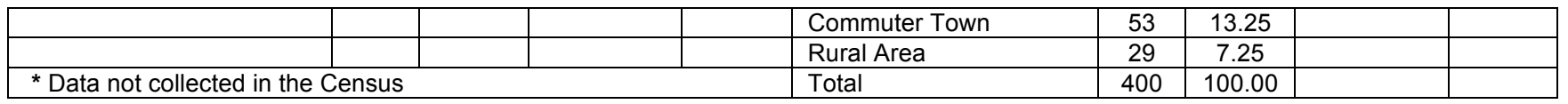

\subsection{Four stage modelling approach}

Transport policy analysis in the GDA uses the Regional Modelling System (RMS), which predicts all-day travel demand and patterns for all modes of transport and 'allows for appraisal of a wide range of potential future transport and land use alternatives' (NTA, 2017). More specifically, the Eastern Regional Model (ERM) was consulted, which considers the modelling area of the GDA. The ERM model was chosen to complement the results of the SP analysis and to provide detailed policy evaluation of the potential 'real life' impacts of the car shedding polices examined in the SP survey. The outputs from the ERM were then used to produce mode share changes. The overall model structure of the ERM is based on the traditional Four Stage Model (FSM) (i.e. Trip Generation, Trip Distribution, Mode Choice and Trip Assignment), which is commonly used to estimate demand and trip making behaviour in a transport network. The trip generation stage of FSM takes place in the National Demand Forecasting Model (NDFM), which is followed by the Full Demand Model (FDM) where the distribution, mode choice and assignment stages are run in a sequential process.

The model produces trip end matrices and trip making patterns for various modes that are then passed onto the FDM, which consists of two main modules: the Choice Model and the Assignment Model (see Figure 1). These two models run in an iterative process until equilibrium is achieved between travel demand and generalised cost. The demand model requires input data on generalised travel costs, travel distances, and journey times, thus, trips from Census and National Travel Survey datasets are matched to the zone systems and networks of the regional models to obtain estimates of these variables. This model then produces trip matrices as outputs from behavioural models representing travel choices such as mode and destination decisions (NTA, 2017). 


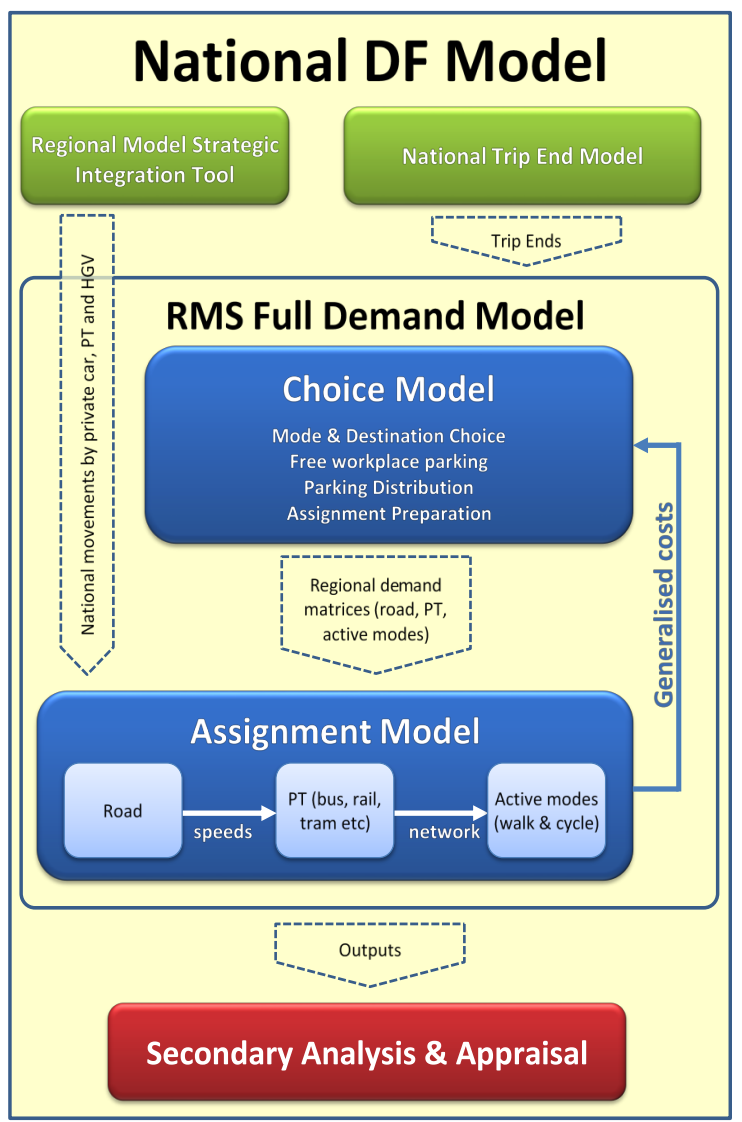

Figure 1 Regional Modelling System Structure (NTA, 2017)

\section{Results}

\subsection{Stated preference results}

\subsubsection{Basic Model}

This section of the paper investigates the effect of offering infrastructural improvements and time savings on the modal choice of walking and cycling in the GDA, in addition to the addressing the perceived risk of taking these modes by reducing adjacent traffic speed limits on certain routes. To provide some initial context to this model, Table 4 details the choice proportions of respondents that selected each of the different modes in the Model.

Table 4 Model sample proportions

\begin{tabular}{|l|c|c|}
\hline Choice & Observation Count & Survey \% \\
\hline Car & 563 & 35.08 \\
\hline Walk & 532 & 33.14 \\
\hline Cycle & 510 & 31.78 \\
\hline Total & 1,605 & 100.00 \\
\hline
\end{tabular}

In this model, the context for the SP scenario was that respondents were offered a mode choice decision for a short distance trip (i.e. between 2-4kms, a distance that is generally deemed suitable for walking and cycling (Census, 2016; Caulfield, 2014)). Considering this distance, the respondents were then asked which of the following three modes: walk, cycle or car, would they most likely choose given policy incentives assigned to the walking and cycling alternatives only.

The base Model results, presented in Table 5, show a low pseudo rho-squared of 0.013 , which suggests that this base model does a poor job at fitting the MNL model 
to the sample dataset and explaining the variances in the data. This finding is mirrored through the high p-value of 0.064 , which marginally exceeds the level of alpha (0.05), meaning that we cannot reject the null hypothesis that the estimated model is no better than the constants only model. Thus, the assumption in Base Model was that the policy scenarios provided to the respondents were not sufficient to ultimately entice those to shift from the car to more sustainable modes of transport. The Walkinfra and Cycletime coefficients were, however, significant at the $80 \%$ confidence level and with a positive sign, meaning that improvements made to walking infrastructure and reductions made to cycle times would increase the utility of walking and cycling as the attribute levels increased. Naturally, as cycling trip times decreased and as more improvements were made to walking infrastructure, the higher the likelihood was of the respondents choosing these modes. The next stage in the analysis was to improve the model and add socio-economic variables to examine how they interact in the model.

Table 5 Base Model Output for Model

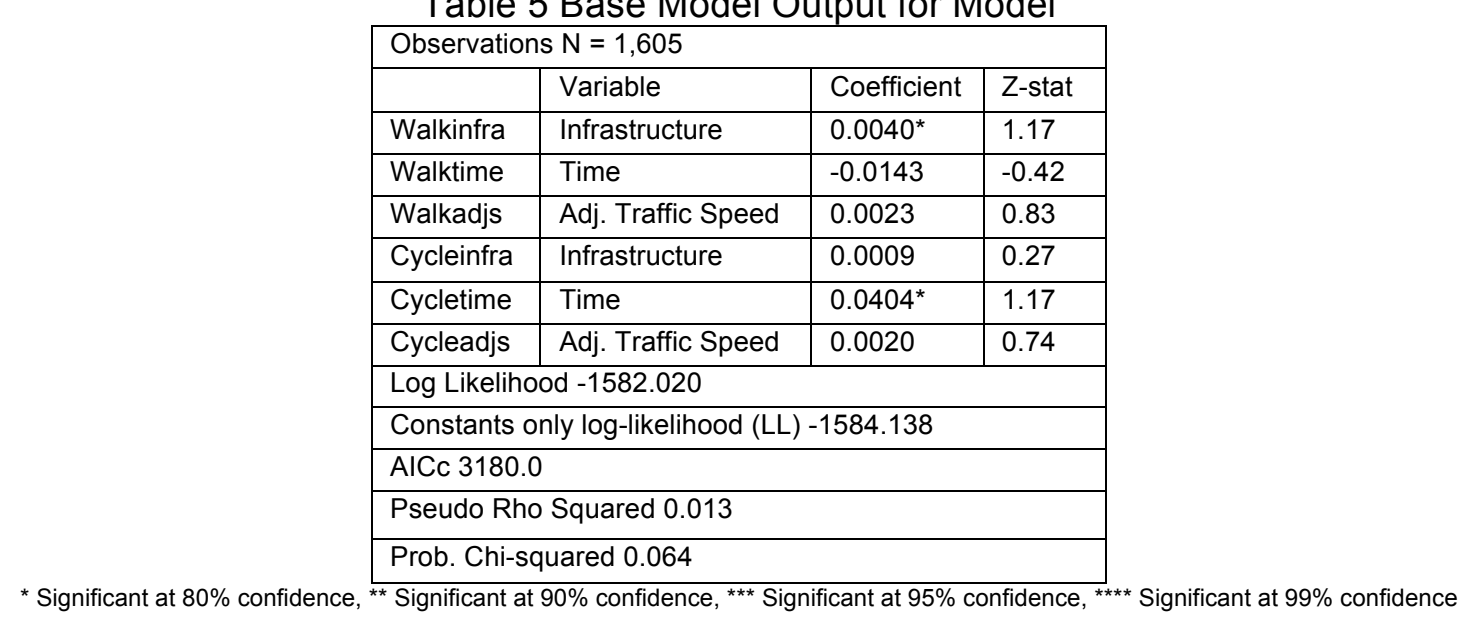

\subsubsection{Extended model}

Table 7 presents the results from the extended model including the sociodemographic variables. As there were many predictors included in the extended model output, the model was reduced to exclude the variables that were nonsignificant, thus the results presented are the predictors that appeared statistically significant alongside the base attributes tested. Table 6 also shows that there were many statistically significant socio-demographic coefficients, which in turn improved the performance of the model from the model presented in Table 5 . The improvements in model fit and the statistical quality of the model were validated through lower log-likelihood and AICc values and a p-value below alpha. A comparison of these statistical indicators is provided in Table 6 . The log-likelihood value for the estimated model was -992.623 , which was an improvement on the loglikelihood of the base comparison model (-1582.020), indicating that the model fit better with the socio-demographic data from the sample.

The pseudo rho-squared values for models in Table 6 of 0.064 and 0.013 can be considered poor, with values closer to 1 indicating a good model fit, (Hensher et al., 2005a; Louviere et al., 2000), it is useful in comparing other larger models to the base comparison. However, as a result of this low hho $^{2}$ value, some caution is required when interpreting the model results. These rho-squared values represent the complexity in predicting human behaviour, particularly in relation to modal choice in hypothetical scenarios, as similar SP studies in the field of transport, such as: Elsayed et al. (2018), Hensher et al. (2015b), Petrik et al. (2013) and Catalano et al. (2008), have also produced $\mathrm{Rho}^{2}$ values lower than one. Efforts were also made by 
the authors to improve the model results presented in this paper by nesting the models and adding further independent variables but neither interventions significantly improved the model fit characteristics.

Table 6 Comparison of model fit and performance indicators for Model 2b

\begin{tabular}{|l|l|l|}
\hline Indicator & Base Model & Extended Model \\
\hline Log-likelihood (LL) & -1582.020 & -992.623 \\
\hline AICc & 3180.0 & 2041.2 \\
\hline Pseudo Rho-squared & 0.013 & 0.064 \\
\hline P-value (chi-squared) & 0.064 & 0.000 \\
\hline
\end{tabular}

With reference to the parameter estimates in Table 7, the results indicated, that the Walkinfra variable increased to the $90 \%$ confidence level, and the coefficient was positive in explaining that as the percentage of evenly surfaced, widened footpaths, separated from traffic increased, the utility of the walking mode also increased. This result suggested that the level of available pedestrian infrastructure had a higher impact on the likelihood of respondents choosing walking as a mode than reductions in trip time or adjacent traffic speed. In relation to the socio-demographic predictors, women were more likely to walk to work or education than men, supported by the negative coefficient; as the gender variable was binary coded as -1 for female and 1 for male; and this variable was statistically significant at the $99 \%$ confidence interval. Older age groups were more likely to walk than younger age cohorts, suggested by the positive sign, which was also statistically significant at $99 \%$ confidence. Furthermore, the coefficients for possessing a driver's licence, owning more than one car and having free parking available at your place of work or college/ University were all negative and statistically significant at the $99 \%$ to $95 \%$ confidence intervals, suggesting that the chances of those individuals opting to walk to work or education were reduced if these features were possessed. The Walklive variable was statistically significant at the $80 \%$ confidence level, with a negative sign, meaning that those living in close proximity to the Dublin city centre showed a higher probability of walking to work or education than those living in the outer suburbs, which is intuitive given the restriction in maximum walking distances.

For the cycling alternative, the case was largely similar, though in addition to this, the results also suggested that reductions in trip time were of more importance in the choice to cycle than infrastructure or adjacent traffic speed, and those not in full time employment, i.e. the unemployed, students, the retired etc., would be more likely to cycle to work or education, based on the 0.1416 coefficient. Finally, those with one or more children, a driver licence and access to free parking were found to be less likely to opt for cycling as a mode, explained by the negative regression coefficients.

Table 7 Extended Model Output

\begin{tabular}{|c|c|c|c|}
\hline \multicolumn{4}{|c|}{ Observations $\mathrm{N}=1605$} \\
\hline & Variable & Coefficient & Z-stat \\
\hline Walkinfra & Infrastructure & $0.0077^{* *}$ & 1.74 \\
\hline Walktime & Time & -0.0124 & -0.28 \\
\hline Walkadjs & Adj. Traffic Speed & 0.0027 & 0.78 \\
\hline Walkgen & Gender & $-0.2778^{* \star * *}$ & -3.17 \\
\hline Walkage & Age & $0.2374^{* * * *}$ & 3.30 \\
\hline Walkedu & Education & $0.0912^{\star * *}$ & 2.19 \\
\hline Walklive & Living location & $-0.0907^{*}$ & -1.30 \\
\hline Walklic & Licence & $-1.3091^{\star * * *}$ & -6.02 \\
\hline Walkown & Car Ownership & $-0.3765^{\star \star \star *}$ & -3.27 \\
\hline Walkpark & Free Parking & $-0.3800^{* \star *}$ & -1.98 \\
\hline Cycleinfra & Infrastructure & 0.0021 & 0.49 \\
\hline
\end{tabular}




\begin{tabular}{|c|c|c|c|}
\hline Cycletime & Time & 0.0363 & 0.84 \\
\hline Cycleadjs & Adj. Traffic Speed & 0.0028 & 0.83 \\
\hline Cycleedu & Education & $0.0907^{* * *}$ & 2.22 \\
\hline Cycleemp & Employment Status & $0.1416^{\star \star \star \star}$ & 3.76 \\
\hline Cyclechil & No. of children & $-0.1109^{\star *}$ & -1.66 \\
\hline Cyclelic & Licence & $-0.5030^{\star \star \star}$ & -2.26 \\
\hline Cyclepark & Free Parking & $-0.5168^{\star * \star *}$ & -2.80 \\
\hline \multicolumn{4}{|c|}{ Log Likelihood -992.623 } \\
\hline \multicolumn{4}{|c|}{ Constants only LL -1060.040} \\
\hline \multicolumn{4}{|c|}{ AICc 2041.2} \\
\hline \multicolumn{4}{|c|}{ Pseudo Rho Squared 0.064} \\
\hline \multicolumn{4}{|c|}{ Prob. Chi-squared 0.000} \\
\hline
\end{tabular}

${ }^{*}$ Significant at $80 \%$ confidence, ${ }^{* *}$ Significant at $90 \%$ confidence, ${ }^{* * *}$ Significant at $95 \%$ confidence, **** Significant at $99 \%$ confidence

\subsubsection{Analysis of incentives}

In conjunction with the SP analysis, respondents were asked what incentives would most likely make them switch to an active mode of transport. Cross tabulations and chi-square tests were also conducted on these incentives in reference to a question in the survey which asked respondents to identify the policy measure that would attract them most to cycle to work if distance was not an issue and if they already owned a bicycle. The results from this analysis, presented in Table 8 , found that improved cycle routes or cycling infrastructure was most attractive as an incentive for cycling, with loans to purchase a bicycle being the least popular measure amongst the sample. The socio-demographic variables of the number of children/ dependents and number of cars available to a household, were found to be statistically significant in relation to this question with p-values of 0.051 and 0.046 , respectively. It was determined from this that those with no children or dependents and one to two cars available to the household were most interested in improved cycle routes as an incentive to cycle to work or education. Both males and females, who were married, and within the 35-54 age group agreed that improved cycling infrastructure, followed by less traffic on the roads, were the measures that were most important to them in the decision to commute by bike to work or education.

Table 8 Cross tabulations and chi-square results

\begin{tabular}{|c|c|c|c|c|c|c|c|c|c|c|c|c|c|c|}
\hline & \multicolumn{2}{|c|}{$\begin{array}{l}\text { Improved } \\
\text { cycle routes }\end{array}$} & \multicolumn{2}{|c|}{$\begin{array}{l}\text { Bicycle facilities } \\
\text { and security }\end{array}$} & \multicolumn{2}{|c|}{$\begin{array}{l}\text { Less traffic } \\
\text { on the roads }\end{array}$} & \multicolumn{2}{|c|}{$\begin{array}{l}\text { Loan to buy } \\
\text { a bicycle }\end{array}$} & \multicolumn{2}{|c|}{$\begin{array}{c}\text { Financial } \\
\text { incentives }\end{array}$} & \multicolumn{2}{|c|}{$\mathrm{N} / \mathrm{A}$} & \multicolumn{2}{|c|}{ Total } \\
\hline Gender $^{a}$ & $\mathrm{~N}$ & $\%$ & $\mathrm{~N}$ & $\%$ & $\mathrm{~N}$ & $\%$ & $\mathrm{~N}$ & $\%$ & $\mathrm{~N}$ & $\%$ & $\mathrm{~N}$ & $\%$ & $\mathrm{~N}$ & $\%$ \\
\hline Male & 76 & 56.7 & 20 & 54.1 & 46 & 60.5 & 5 & 62.5 & 18 & 50.0 & 37 & 44.7 & 203 & 54.0 \\
\hline Female & 58 & 43.3 & 17 & 45.9 & 30 & 39.5 & 3 & 37.5 & 18 & 50.0 & 47 & 55.3 & 173 & 46.0 \\
\hline Total & 134 & 100.0 & 37 & 100.0 & 76 & 100.0 & 8 & 100.0 & 36 & 100.0 & 85 & 100.0 & 376 & 100.0 \\
\hline $\operatorname{Age}^{b}$ & & & & & & & & & & & & & & \\
\hline 18-34 years old & 35 & 25.7 & 12 & 32.4 & 19 & 25 & 4 & 50.0 & 12 & 33.3 & 26 & 30.6 & 108 & 28.6 \\
\hline $35-54$ years old & 73 & 53.7 & 21 & 56.8 & 42 & 55.3 & 3 & 37.5 & 19 & 52.8 & 41 & 48.2 & 199 & 52.6 \\
\hline 55-64 years old & 20 & 14.7 & 3 & 8.1 & 13 & 17.1 & 1 & 12.5 & 4 & 11.1 & 14 & 16.5 & 55 & 14.6 \\
\hline $65+$ years old & 8 & 5.9 & 1 & 2.7 & 2 & 2.6 & 0 & 0.0 & 1 & 2.8 & 4 & 4.7 & 16 & 4.2 \\
\hline Total & 136 & 100.0 & 37 & 100.0 & 76 & 100.0 & 8 & 100.0 & 36 & 100.0 & 85 & 100.0 & 378 & 100.0 \\
\hline Marital status ${ }^{c}$ & & & & & & & & & & & & & & \\
\hline Single & 58 & 43.6 & 15 & 40.5 & 31 & 41.9 & 3 & 37.5 & 14 & 40.0 & 33 & 38.8 & 154 & 41.4 \\
\hline Married & 64 & 48.1 & 18 & 48.6 & 39 & 52.7 & 4 & 50.0 & 18 & 51.4 & 47 & 55.3 & 190 & 51.1 \\
\hline
\end{tabular}




\begin{tabular}{|c|c|c|c|c|c|c|c|c|c|c|c|c|c|c|}
\hline $\begin{array}{l}\text { Separated or } \\
\text { Divorced }\end{array}$ & 11 & 8.3 & 4 & 10.8 & 4 & 5.4 & 1 & 12.5 & 3 & 8.6 & 5 & 5.9 & 28 & 7.5 \\
\hline Total & 133 & 100.0 & 37 & 100.0 & 74 & 100.0 & 8 & 100.0 & 35 & 100.0 & 85 & 100.0 & 372 & 100.0 \\
\hline \multicolumn{15}{|c|}{ Number of children/dependents ${ }^{d}$} \\
\hline None & 70 & 51.5 & 1 & 35.1 & 35 & 46.1 & 2 & 25.0 & 17 & 48.6 & 33 & 39.3 & 170 & 45.2 \\
\hline One & 20 & 14.7 & 7 & 18.9 & 6 & 7.9 & 4 & 50.0 & 8 & 22.9 & 14 & 16.7 & 59 & 15.0 \\
\hline Two or more & 46 & 33.8 & 17 & 45.9 & 35 & 46.1 & 2 & 25.0 & 10 & 28.6 & 37 & 44.0 & 147 & 39.1 \\
\hline \multicolumn{15}{|c|}{ Number of cars owned } \\
\hline One & 78 & 46.4 & 22 & 51.2 & 45 & 47.4 & 4 & 30.8 & 37 & 51.9 & 43 & 41.0 & 219 & 46.0 \\
\hline Two or More & 65 & 38.7 & 15 & 34.9 & 29 & 30.5 & 3 & 23.1 & 22 & 42.3 & 46 & 43.8 & 180 & 37.8 \\
\hline None & 25 & 14.9 & 6 & 14.0 & 21 & 22.1 & 6 & 46.2 & 3 & 5.8 & 16 & 15.2 & 77 & 16.2 \\
\hline Total & 168 & 100.0 & 43 & 100.0 & 95 & 100.0 & 13 & 100.0 & 52 & 100.0 & 105 & 100.0 & 476 & 100.0 \\
\hline
\end{tabular}

\subsection{Four stage modelling results}

\subsubsection{Parameter Modifications}

The cycle network in the active modes assignment model, was firstly modified to take account of improved cycle infrastructure in the GDA, as examined in the SP survey. Cycle speeds were increased in line with the SP policy scenarios, on certain links in the network to act as a proxy for the provision of segregated cycle infrastructure. Pedestrian speeds were similarly increased to account for walking mode improvements, such as signalling changes and widening footpaths (i.e. more street space assigned to pedestrians to increase the flow of pedestrians) and decluttering footpaths to remove obstacles that may hinder pedestrian flows.

To account for the attribute levels included in the SP study, three overarching modelling scenarios were examined: a Do Nothing/ Base, a Do Something, and a Do Maximum scenario. In each of these scenarios, changes to the network were introduced in multiple model runs. The organisational structure of the parameter changes made in the ERM is outlined in Table 9.

Table 9 Policy incentives and model parameter changes

\begin{tabular}{|c|c|c|c|c|}
\hline \multirow{2}{*}{ Modes } & \multirow{2}{*}{ Policy Incentives/ Measures } & \multicolumn{2}{|c|}{ Effects of Incentives on trip attributes } & \multirow{2}{*}{$\begin{array}{l}\text { Justification for model } \\
\text { changes }\end{array}$} \\
\hline & & Infrastructure & Time & \\
\hline \multirow[t]{2}{*}{ Cycling } & $\begin{array}{l}\text { Increase cycle lane continuity, } \\
\text { incidence of fully segregated } \\
\text { cycle lanes }\end{array}$ & \multirow{2}{*}{$\begin{array}{l}\% \text { increase in the } \\
\text { incidence of fully } \\
\text { segregated cycle lanes }\end{array}$} & \multirow{2}{*}{$\begin{array}{l}\% \text { reduction in trip time from } \\
\text { improved cycling infrastructure }\end{array}$} & \multirow{2}{*}{$\begin{array}{l}\text { Increase in cycle speeds } \\
\text { on certain links act as a } \\
\text { proxy for an increase in } \\
\text { segregated cycle } \\
\text { infrastructure }\end{array}$} \\
\hline & $\begin{array}{l}\text { Priority given to cyclists over } \\
\text { motorists at junctions }\end{array}$ & & & \\
\hline Walking & $\begin{array}{l}\text { Improved pedestrian priority at } \\
\text { junctions, signalling changes, } \\
\text { greater amount of street space } \\
\text { assigned to pedestrians }\end{array}$ & $\begin{array}{l}\text { Reclaiming street space } \\
\text { for pedestrians, priority } \\
\text { over motorised traffic }\end{array}$ & $\begin{array}{l}\% \text { reduction in trip times from } \\
\text { shorter wait times at junctions } \\
\text { and crossings, reduction in } \\
\text { pedestrian congestion }\end{array}$ & $\begin{array}{l}\text { Increase in pedestrian } \\
\text { speeds acts as a proxy } \\
\text { for pedestrian priority at } \\
\text { junctions. }\end{array}$ \\
\hline
\end{tabular}

Active mode parameter modifications were made to represent improvements made to walking and cycling infrastructure, leading to reductions in trip time and the perceived level of risk of these modes. The demand of walking and cycling, produced from the model is assigned separately reflecting the difference in the pedestrian and cycling networks. Walk trips are assigned to the shortest distance route, assuming a 
constant walk speed of $5.1 \mathrm{~km} / \mathrm{h}$, and cycle trips are assigned based on the quickest journey time based on available route infrastructure, e.g. segregated cycleways (NTA, 2017). The active modes model employs as simple 'All or Nothing' shortest path approach, with no capacity or 'speed-flow' effects, i.e. 'the speed on the links is not affected by the number of pedestrians or cyclists using that link' (NTA, 2017). All or Nothing assignment refers to when travel times on links are defined beforehand, thus the shortest paths between origin and destination are already determined. The trips are then assigned accordingly to links with the shortest trip times (Ortúzar and Willumsen, 2011).

To account for improvements made to pedestrian priority and more street space being assigned to pedestrians, pedestrian speeds were accordingly modified. In line with the Do Something and Do Maximum scenarios, $25 \%$ and $35 \%$ increases in pedestrian speeds were made to represent greater pedestrian priority, thus simulating a minimisation of wait times for pedestrians at junctions due to signalling changes implemented, in addition to the de-cluttering and widening of footpaths. These percentage increases were applied to the default $5.1 \mathrm{~km} / \mathrm{h}$ constant pedestrian speed coded in the active modes assignment model.

In order to represent improvements in cycle infrastructure, modifications were similarly made to cycling speeds on certain links in the cycle network that correspond to little or no cycling infrastructure. In the ERM, the quality of service of cycle infrastructure or 'cycle friendliness' is modelled in terms of changes in cycling speeds. The base cycle speed (corresponding to links without any cycling infrastructure) is set to a minimum of $12 \mathrm{~km} / \mathrm{h}$, with the maximum cycling speed set to $20 \mathrm{~km} / \mathrm{h}$, which represents links with the fully segregated cycle infrastructure/ lanes or greenways. These speeds are calculated based on data from the National Household Travel Survey (2012). A list of the full range of modelled cycle speeds in the ERM network, based on the quality of service grading system is displayed in Table 10.

Table 10 Cycle speeds based on quality of service data (NTA, 2017)

\begin{tabular}{|c|l|c|}
\hline Grade & \multicolumn{1}{|c|}{ Quality of Service } & Modelled Cycle Speed $(\mathrm{km} / \mathrm{h})$ \\
\hline A+ & $\begin{array}{l}\text { High quality well maintained surface, no manholes, gullies or } \\
\text { other ironworks }\end{array}$ & 20 \\
\hline A & High quality well maintained surface, with manholes, gullies & 19.2 \\
\hline B & $\begin{array}{l}\text { Surface with deteriorating surface or poorly maintained with } \\
\text { debris evident }\end{array}$ & 18.4 \\
\hline C & Undulating, cracked, generally an unsatisfactory ride experience & 17.2 \\
\hline D & $\begin{array}{l}\text { Very poor ride quality with severe undulations, concrete aprons, } \\
\text { very poorly maintained surface. Unsuitable and needs action }\end{array}$ & 15.2 \\
\hline
\end{tabular}

To represent the Do Something and Do Maximum policy scenarios in the ERM, $40 \%$ and $60 \%$ increases in the cycle speeds of links below the $15.2 \mathrm{~km} / \mathrm{h}$ average cycle speed were made. In other words, cycling speeds were increased on links indicated to have poor or no cycle infrastructure in place.

\subsubsection{Active Modes Changes Output}

The alterations made to the walking and cycling network in the ERM were centred on increases to pedestrian and cycling speeds as proxies for improvements made to infrastructure for pedestrians and cyclists in addition to increasing pedestrian and cycling priority at junctions. The results set out in Table 11 show the mode shares in the GDA produced from the ERM based changes in the 2012 Base Scenario.

In the 2012 Base Scenario Do Something scenario, shown in Table 11, the 25\% increase in pedestrian speeds and $40 \%$ increase in cycle speeds, resulted in a $4.42 \%$ increase in the mode share of walking for all trip purposes. This was as a 
result of improving cycling and pedestrian infrastructure (i.e. addressing pedestrian and cyclist priority at junctions, increasing the incidence of widened and uncluttered footpaths, and fully segregated cycle lanes). Of this increase, $1.33 \%$ came from private cars, $2.12 \%$ from PT and $0.97 \%$ from cycling. The mode share of walking then increased further by $1.53 \%$ in the Do Maximum scenario, bringing the share to $29.85 \%$, with $1.91 \%$ of private car users, $2.81 \%$ of PT users and $1.23 \%$ of cyclists switching to walking. The key result from this particular model run was that the largest decrease in the mode share of private cars, for all trip purposes, was achieved at $1.91 \%$. This suggested that investing in pedestrian infrastructure in particular, could be an effective means of encouraging a mode shift away from private car usage in the GDA.

By isolating commute trips estimated in the model, it was also possible to observe the mode choice behaviour of commuters in the GDA. The mode share for private cars was markedly higher for commute trips at $72.89 \%$ for the Base scenario, which marginally fell to $72.08 \%$ in the Do Something scenario. Walking was found to have the only increase across the modes, with an increase of $2.38 \%$ in the Do Something scenario and $3.17 \%$ in the Do Maximum scenario. Of this $3.17 \%$ increase in the Do Maximum scenario, $1.67 \%$ came from PT, $0.76 \%$ from cyclists and $0.75 \%$ came from private car users shifting to walking. These results showed, given infrastructure improvements made in both the pedestrian and cycling network, that pedestrians could be more sensitive to such changes than cyclists, represented by the mode share increases for walking and decreases for cycling. This suggests that, if walk trip times were reduced due to shorter wait times at junctions, and wider and de-cluttered footpaths, cyclists (who were also incentivised) along with PT users and private car drivers, would be attracted to mode shift to walking.

Table 11 Active modes (walking and cycling) changes output for the 2012 Base Scenario

\begin{tabular}{|c|c|c|c|c|c|}
\hline \multicolumn{6}{|c|}{ All Trip Purposes (2012 Strategy) } \\
\hline \multicolumn{2}{|l|}{ Base Scenario } & \multicolumn{2}{|c|}{$\begin{array}{l}\text { Do Something Scenario } \\
25 \% \text { increase in Ped. speeds and } \\
40 \% \text { increase in cycle speeds }\end{array}$} & \multicolumn{2}{|c|}{$\begin{array}{l}\text { Do Maximum Scenario } \\
35 \% \text { increase in Ped. speeds and } \\
60 \% \text { increase in cycle speeds }\end{array}$} \\
\hline No. of Trips: & $5,048,523$ & No. of Trips: & $5,050,470$ & No. of Trips: & $5,050,691$ \\
\hline Modes & Mode Share \% & Mode Share \% & $\begin{array}{l}\% \text { diff. from } \\
\text { Base }\end{array}$ & Mode Share \% & $\begin{array}{l}\% \text { diff. from } \\
\text { Base }\end{array}$ \\
\hline Car & 62.23 & 60.90 & -1.33 & 60.32 & -1.91 \\
\hline $\begin{array}{l}\text { Public } \\
\text { Transport }\end{array}$ & 9.69 & 7.57 & -2.12 & 6.88 & -2.81 \\
\hline Walk & 23.90 & 28.32 & +4.42 & 29.85 & +5.95 \\
\hline Cycle & 4.18 & 3.21 & -0.97 & 2.95 & -1.23 \\
\hline Total & 100.00 & 100.00 & & 100.00 & \\
\hline \multicolumn{6}{|c|}{ Commute Trip Purpose (Base Scenario 2012) } \\
\hline \multicolumn{2}{|l|}{ Base Scenario } & \multicolumn{2}{|c|}{$\begin{array}{l}\text { Do Something Scenario } \\
25 \% \text { increase in Ped. speeds and } \\
40 \% \text { increase in cycle speeds }\end{array}$} & \multicolumn{2}{|c|}{$\begin{array}{l}\text { Do Maximum Scenario } \\
35 \% \text { increase in Ped. speeds and } \\
60 \% \text { increase in cycle speeds }\end{array}$} \\
\hline No. of Trips: & $1,046,797$ & No. of Trips: & $1,047,419$ & No. of Trips: & $1,047,515$ \\
\hline Modes & Mode Share \% & Mode Share \% & $\begin{array}{l}\text { \% diff. from } \\
\text { Base }\end{array}$ & Mode Share \% & $\begin{array}{l}\text { \% diff. from } \\
\text { Base }\end{array}$ \\
\hline
\end{tabular}




\begin{tabular}{|l|c|c|c|c|c|}
\hline Car & 72.89 & 72.08 & -0.81 & 72.14 & -0.75 \\
\hline $\begin{array}{l}\text { Public } \\
\text { Transport }\end{array}$ & 10.58 & 9.58 & -1.00 & 8.91 & -1.67 \\
\hline Walk & 12.78 & 15.16 & +2.38 & 15.95 & +3.17 \\
\hline Cycle & 3.75 & 3.19 & -0.57 & 3.00 & -0.76 \\
\hline Total & 100.00 & 100.00 & & 100.00 & \\
\hline
\end{tabular}

The mode share output from the 2035 GDA Strategy model runs, shown in Table 12 , comprised of the introduction of large public transport projects such as a new underground line, a number of new tram lines and the Bus Connects project (large bus priority project) (NTA, 2016). This increase in the availability of PT modes was reflected in the Base Scenario mode shares, which showed a mode split of $58.40 \%$ for Car, $16.18 \%$ for PT, $22.18 \%$ for Walk, and $3.24 \%$ for Cycle. This equated to an increase in the mode share of PT of $6.49 \%$, from the 2012 Base Scenario to the 2035 GDA Strategy. The share of private cars in 2035 was also found to be noticeably lower when compared to 2012 , in response to the range of projects introduced in the period of the 2035 strategy, as this mode share fell by $3.83 \%$, from $62.23 \%$ to $58.40 \%$ during this period.

However, the aim of the changes in the active modes' scenario was to further incentivise walking and cycling over other modes in the model. This was represented in 2035 mode shares output from the Do Something and Maximum scenarios, shown in Table 12, where, the mode share of walking rose by up to $6.30 \%$ in the Do Maximum scenario for all trip purposes and 3\% for the commute trip purpose only. Pedestrians were again more elastic to changes in speeds than cyclists as there were decreases in the mode shares of cycling of up to $0.96 \%$ for all trip purposes and up to $0.51 \%$ for the commute trip purpose. Nevertheless, the model modifications made to cycling and pedestrian speeds also came at the cost of a significant mode shift away from PT modes, similarly shown in the 2012 scenario. In the 2035 scenario, reductions in the mode share of PT of up to $4.07 \%$ in the Do Maximum scenario for all trip purposes, and up to $2.12 \%$ for the commute purpose alone, were estimated. In this scenario, such a significant shift away from PT would not necessarily be a negative consequence given the large increase in the mode shares of walking and reduction in private car trips. Overall, these results showed that the introduction of the active mode incentives outlined in Table 9 resulted in a $4.58 \%$ increase in the mode share of walking from the Base case scenario 2012 to the Do Maximum 2035 Strategy.

Table 12 Active mode changes output for the 2035 GDA Strategy

\begin{tabular}{|c|c|c|c|c|c|}
\hline \multicolumn{6}{|c|}{ All Trip Purposes (2035 Strategy) } \\
\hline \multicolumn{2}{|c|}{ Base Scenario } & \multicolumn{2}{|c|}{$\begin{array}{l}\text { Do Something Scenario } \\
25 \% \text { increase in Ped. speeds and } \\
40 \% \text { increase in cycle speeds }\end{array}$} & \multicolumn{2}{|c|}{$\begin{array}{l}\text { Do Maximum Scenario } \\
35 \% \text { increase in Ped. speeds and } \\
60 \% \text { increase in cycle speeds }\end{array}$} \\
\hline No. of Trips: & $5,984,781$ & No. of Trips: & $5,987,783$ & No. of Trips: & $5,991,301$ \\
\hline Modes & Mode Share \% & Mode Share \% & $\begin{array}{l}\% \text { diff. from } \\
\text { Base }\end{array}$ & Mode Share \% & $\%$ diff. from Base \\
\hline Car & 58.40 & 57.68 & -0.72 & 57.07 & -1.33 \\
\hline PT & 16.18 & 13.20 & -2.98 & 12.11 & -4.07 \\
\hline Walk & 22.18 & 26.83 & +4.65 & 28.48 & +6.30 \\
\hline Cycle & 3.24 & 2.29 & -0.96 & 2.35 & -0.89 \\
\hline Total & 100.00 & 100.00 & & 100.00 & \\
\hline \\
\hline \multicolumn{2}{|c|}{ Base Scenario } & \multicolumn{2}{|c|}{$\begin{array}{l}\text { Do Something Scenario } \\
25 \% \text { increase in Ped. speeds and } \\
40 \% \text { increase in cycle speeds }\end{array}$} & \multicolumn{2}{|c|}{$\begin{array}{l}\text { Do Maximum Scenario } \\
35 \% \text { increase in Ped. speeds and } \\
60 \% \text { increase in cycle speeds }\end{array}$} \\
\hline No. of Trips: & $1,268,512$ & No. of Trips: & $1,266,550$ & No. of Trips: & $1,266,948$ \\
\hline Modes & Mode Share \% & Mode Share \% & $\begin{array}{l}\text { \% diff. from } \\
\text { Base }\end{array}$ & Mode Share \% & $\%$ diff. from Base \\
\hline Car & 68.76 & 68.20 & -0.56 & 68.26 & -0.50 \\
\hline PT & 18.75 & 17.58 & -1.17 & 16.64 & -2.12 \\
\hline Walk & 10.35 & 12.59 & +2.25 & 13.35 & +3.00 \\
\hline
\end{tabular}




\begin{tabular}{|l|c|c|c|c|c|}
\hline Cycle & 2.14 & 1.63 & -0.51 & 1.76 & -0.38 \\
\hline Total & 100.00 & 100.00 & & 100.00 & \\
\hline
\end{tabular}

\section{Discussion and conclusions}

In analysing the results of this survey, it was found that individual commuters do need a proper incentive to disrupt, in some cases, long-standing commuting habits. Nevertheless, if such incentives can lead to tangible time and cost savings for the commuter, then this is estimated to result in some sustainable mode choice behaviour. The choice scenarios were constructed to ask the respondents to deliberate on the attributes that were of real importance to them and from this they were prompted to make trade-offs between three modes of transport in each scenario. If the respondent was not attracted by the incentives presented or if, given their socio-demographic characteristics, the sustainable modes were not able to be realistically considered, then the status-quo 'drive alone' option was included as a no-choice alternative, as no incentives nor disincentives were applied to it. Yet, from examining the results it was found that the sample responded positively to the experiment, to the extent that the car alternative was placed second or even third in order of preference. This indicated that there is convincing evidence for investing more attention to providing commuters with more enticements to switch to active modes.

The findings produced from the SP experiment are similarly comparable to other work in this area. For example, the MNL results produced showed that respondents were more willing to choose cycling as mode given time savings made in their commute, which is in line with findings from Li, et al. (2017), Abraham, et al. (2012) and Stinson and Bhat (2003) who found that commuters would be more willing to cycle given short travel times and would prefer routes with continuous cycling infrastructure, less traffic and few traffic controls.

The SP results also showed that the level of pedestrian infrastructure was of more important in the mode choice for walking and trip time was of prime consideration for those opting for cycling as a mode. However, those with children, a driving licence, access to a car and free workplace parking were less likely to choose either active mode. The FSM results found that pedestrians, rather than cyclists or other mode users, in the GDA were most sensitive to parameter changes made in both the Base 2012 and forecast 2035 scenarios. This was particularly evident as walking experienced the largest and, in some cases, the only increase in mode share across all of the modes modelled. Thus, it is suggested that pedestrian infrastructure should arguably be prioritised over cycling infrastructure initially, as indeed the majority of commuters use pedestrian facilities at some point of their journey and so investment in walking infrastructure will benefit most commuters. Much of the emphasis in the past in Dublin and other cities has been on increasing cycling infrastructure. However, the results of this paper emphasise the importance of not neglecting walking infrastructure as it is in this mode that the most significant increases might be experienced with increased investment. In addition to this, increased promotion of active mode use would reduce the impact of negative externalities associated with motorised transport, namely, harmful emissions and congestion as a result of a $2 \%$ reduction in the mode share of private cars in the GDA. Furthermore, while the health (i.e. reduced mortality risk) and wellbeing benefits associated with the physical activity involved in active modes use are a key consideration, this was outside of the scope of this paper and will be examined in a later study. 


\section{Acknowledgement}

The authors would like to thank the Environmental Protection Agency of Ireland for funding this research under the Greening Transport project.

\section{References}

Abraham, J., E., McMillan, S., Brownlee, A., T., Hunt, J., D. (2002) Investigation of Cycling Sensitivities, $81^{\text {st }}$ Annual Meeting of the Transportation Research Board, Washington, DC., pp. 1-12.

Bovy, P., Bradley, P. (1985) Route choice analyzed with stated preference approaches. Transportation Research Record, Vol. 1037, Washington DC: TRB, National Research Council.

Carroll, P., J., Caulfield, B., and Ahern, A. (2017a) Examining the potential for carshedding in the Greater Dublin Area, Transportation Research Part A: Policy and Practice, Vol. 106, pp. 440-452.

Carroll, P., Caulfield, B., Ahern, A. (2017b) Work Package 3 - Examining Smarter Travel Options to Reduce Emissions, Environmental Protection Agency, p1 - 84

Caulfield, B. (2014) Re-cycling a city - examining the growth of cycling in Dublin, Transportation Research Part A: Policy and Practice, Vol. 61, pp. 216-226.

Caulfield, B., Brick, E., McCarthy, O., T. (2012) Determining bicycle infrastructure preferences - A case study of Dublin, Transportation Research Part D, Vol. 17, pp. 413-417.

Caulfield, B., Leahy., J. (2011) Learning to cycle again: examining the benefits of providing tax-free loans to purchase new bicycles, Research in Transportation Business \& Management, 2, pp.42 - 47

Central Statistics Office of Ireland (2017) Census 2016 Summary Results - part 2. Available at: www.cso.ie/en/csolatestnews/presspages/2017/census2016summaryresults-part2/. [Accessed on: 29/06/17].

Catalano, M., Lo Casto, B., Migliore, M. (2008) Car-sharing demand estimation and urban transport demand modelling using stated preference techniques, European Transport, Vol. 40, pp. 33- 50.

Climate Action Network Europe (2019) Off Target, Ranking of EU Countries' ambition and progress to fight climate change, Available at: http://www.caneurope.org/docman/climate-energy-targets/3357-off-target-ranking-ofeu-countries-ambition-and-progress-in-fighting-climate-change/file. [Accessed on: 26/02/2019].

Department of Public Expenditure and Reform (2018) National Development Plan 2018-2027. Dublin: Department of Public Expenditure and Reform.

Dublin City Council (2017) Speed limits in your area, Available at: http://www.dublincity.ie/main-menu-services-roads-and-traffic-general-trafficmeasures/speed-limits-your-area. [Accessed on: 20/02/2018]. 
Elsayed, A., Grip, A., Fourage, D., Montizaan, R. (2018) Gradual retirement, financial incentives, and labour supply of older workers: Evidence form a stated preference analysis, Journal of Economic Behaviour and Organization, Vol. 000, pp. 1-18.

European Commission (2012) Europe 2020: Europe's growth strategy. Brussels: European Commission.

European Cyclists' Federation (2017) Academic research on cycling is booming, Available at: https://ecf.com/news-and-events/news/academic-research-cyclingbooming. [Accessed on: 26/03/2018].

EPA (2016) Ireland's Environment: An Assessment 2016. Wexford: Environmental Protection Agency of Ireland.

European Platform for Mobility Management (2019), Available at: http://www.epomm.eu/index.php?id=2621. [Accessed on: 27/02/2019].

Guo, Z., and Loo, B., P.Y. (2013) Pedestrian environment and route choice: evidence from New York City and Hong Kong, Journal of Transportation Geography, Vol. 28, pp. 124-136.

Hensher, D., A., Rose, J., M., and Greene, W., H. (2015a) Applied Choice Analysis: Second Edition. Cambridge: Cambridge University Press.

Hensher, D., A., Ho, C., Mulley, C. (2015b) Identifying preferences for public transport investments under a constained budget, Transportation Research Part $A$ : Policy and Practice, Vol. 72, pp. 27-46.

Hine, J. (1996) Pedestrian travel experiences: assessing the impact of traffic on behaviour and perceptions of safety using an in-depth interview technique, Journal of Transport Geography, Vol. 4, No. 3, pp. 179-199.

Hopkinson, P., Wardman, M., (1996) Evaluating the demand for new cycle facilities, Transport Policy Vol. 2, Issue 4, pp. 241-249.

INRIX (2019) INRIX 2018 Global Traffic Score Card, Available at: http://inrix.com/scorecard/, [Accessed on: 27/02/2019].

Louviere, J.J., Hensher, D.A., Swait, J. (2000) Stated Choice Methods. Cambridge University Press, Cambridge.

Li, S., Muresan, M., and Fu, L. (2017) Cycling in Toronto: route choice behaviour and implications to infrastructure planning, $96^{\text {th }}$ Annual Meeting of the Transportation Research Board, Washington DC, pp. 1-19.

Muraleetharan, T., Hagiwara, T., Adachi, T., Kagaya, S. (2005) Method to determine pedestrian level-of-service for crosswalks at urban intersections, Journal of the Eastern Society for Transportation Studies, Vol. 6, pp. 127-136.

NTA (2019) NTA sets out proposals to improve bus journey times for passengers in Dublin, Available at: https://www.nationaltransport.ie/news/nta-sets-out-proposals-toimprove-bus-journey-times-for-passengers-in-dublin/

[Accessed on: 27/02/2019]. 
NTA (2018) Statement of Strategy 2018-2022, Available at: https://www.nationaltransport.ie/wpcontent/uploads/2018/03/NTA Statement_of_Strategy_2018-2022_ENGLISH.pdf. [Accessed on: 26/03/2018].

NTA (2013) GDA Cycle Network Plan. Dublin: National Transport Authority.

NTA (2016) Transport Strategy for the Greater Dublin Area 2016 -2035. Dublin: National Transport Authority.

Nilsson, G. (2004) Traffic safety dimensions and the Power Model to describe the effect of speed on safety. Lund: Lund Institute of Technology, Department of Technology and Society, Traffic Engineering.

Ortúzar, J., Willumsen, L.G., 1994. Modelling Transport. Wiley, West Sussex.

O'Connor, D., Caulfield, B. Level of Service and the transit neighborhood Observations from Dublin city and suburbs. Research in Transportation Economics, 69, 2018, p59-67

Petrik, O., Silva, J., Moura, F. (2013) Stated preference surveys in transport demand modelling: disengagement of respondents, WDTR 2013: Selected Proceedings, Rio de Janeiro, pp. 1-20.

Pilar, J.G., Nogal, M., Caulfield, B., Pilla, F. (2016) Perceptually important points of mobility patterns to characterize bike sharing systems: The Dublin Case, Journal of Transport Geography, 54, pp.228 - 239

Pooley, C., G., Horton, D., Scheldeman, G., Mullen, C., Jones, T., Tight, M., Jopson, A., Chisholm, A. (2013) Policies for promoting walking and cycling in England: A view from the street. Transport Policy, Vol. 27, pp. 66-72.

Pooley, C., G., Horton, D., Scheldeman, G., Tight, M., Jones, T., Chisholm, A., Harwatt, H., Jopson, A. (2011) Household decision-making for everyday travel: a case study of walking and cycling in Lancaster (UK), Journal of Transport Geography, Vol. 19, pp. 1601-1607.

Pucher, J., Buehler, R. (2017) Cycling towards a more sustainable transport future, Transport Reviews, Vol. 37, No. 6, pp. 689-694.

Short, J., Caulfield, B. (2014) The safety challenge of increased cycling. Transport Policy, Vol. 33, pp. 154-165.

Stinson, M., A., Bhat, C., R. (2003) An analysis of commuter bicyclist route choice using a stated preference survey, Transportation Research Record, Vol. 1828, pp. 107-115.

Transport for Ireland (2017) Two thirds of passengers into Dublin city centre use sustainable transport modes, Available at: https://www.transportforireland.ie/twothirds-of-passengers-into-dublin-city-centre-use-sustainable-transport-modes/.

[Accessed on: 13/03/2018]. 
Washbrook, K., Haider, W., Jaccard, M. (2006) Estimating commuter mode choice: a discrete choice analysis of the impact of road pricing and parking charges. Transportation, Vol. 33, pp. 621- 639.

World Energy Council (2019), Available at: https://wecindicators.enerdata.net/transport-co2-emissions-per-capita.html [Accessed on 27/02/2019]

World Health Organization (2015) Economic Cost of the Health Impact of Air Pollution in Europe: Clean Air, Health and Wealth. Available at:

http://www.euro.who.int/ data/assets/pdf file/0004/276772/Economic-cost-healthimpact-air-pollution-en.pdf. [Accessed on: 12/03/2018]. 